\title{
Post-traumatic Stress Disorder (Traumatic War Neurosis) and Concurrent Psychiatric Illness Among Australian Vietnam Veterans. A Controlled Study
}

\author{
Dr Bruce Boman, \\ NB, BS, MRANZCP \\ Senior Specialist (Psychiatry), Dept of Veterans' Affairs, Repatriation General Hospital, Concord, New South Wales, Australia
}

SUMMARY: Depression, anxiety, irritability with unpredictable explosions of aggressive behaviour, impulsivity, suicidal actions and substance abuse have been repeatedly observed among ex-servicemen from World War II in psychiatric treatment settings.

In the most recent American Psychiatric Association classification of mental disorders the category of Post Traumati Stress Disorder (PTSD) was introduced, replacing the earlier Traumatic War Neurosis and the above cluster of symptom were included as associated features of this disorder.

Two recent uncontrolled studies on U.S. Vietnam veterans receiving psychiatric care supported the linkage of PTSfi with these abnormalities. However, the present controlled study found these associated features occurred with equad frequencies among one group of psychiatrically hospitalised Australian Vietnam veterans with PTSD and another greuB not so afflicted.

Reservations, then, should be harboured about ascribing all the presented psychopathology and behavioural abnormalities of ex-servicemen to the stress of their war service.

\section{Introduction}

The publication of the third edition of the Diagnostic \& Statistical Manual of the American Psychiatric Association (DSM-III) ${ }^{1}$ heralded a major advance in psychiatric nosology. One of DSM-III's key features is the employment of operational criteria for each diagnostic category. That is, for each disorder a specific set of symptoms and signs is provided which must be present for a diagnosis to be made.

For clinicians working with victims of overwhelmingly stressful events, one of DSM-III's most significant conceptual innovations is the introduction of the category of Post-traumatic Stress Disorder (PTSD). This had gathered together a seemingly disparate collection of entities including battle shock, traumatic neurosis, war neurosis, Konzentrations - lager (KZ) syndrome and the post-disaster syndrome, thus highlighting the ubiquity of the emotional responses individuals manifest when faced with a psychological trauma of overpowering magnitude that is outside the range of routine human experience.

The main diagnostic points of PTSD are:

a. A repetitive re-experiencing of the traumatic events via, for example, recurrent, intrusive thoughts, dreams and 'flashbacks', as well as an intensification of symptoms by exposure to events that reawaken recollections of the trauma.

b. A defensive numbing of responsiveness to and reduced involvement with the world at large, as manifested by such phenomena as feelings of estrangement from close family members, detachment from old interests and activities, a constricted effect ang depersonalisation experiences. Active avoidance of situations that arouse painful memories of the traumetie event is often, also, noted.

c. A variety of autonomic, dysphoric and cogni商高 symptoms including exaggerated startle responses insomnia, defective concentration and memory, ang guilt about surviving when companions perished.

DSM-III describes a number of symptoms an behavioural abnormalities which it claims common $\overrightarrow{\mathrm{g}}$ complicate or are associated with PTSD. These include depression, anxiety, increased irritability linked wi無 sporadic and unpredictable explosions of aggressive behaviour, impulsivity, substance use disorders, suicida actions, occupational impairment and interference wit interpersonal relationships. Certainly such a sympto cluster has regularly been spoken of as characteristic ex-servicemen receiving psychiatric care. For exampl a 1941 study of traumatic neurosis in a US veterans hospital found that all chronic cases invariab demonstrated irritability, proclivity to explosivery aggressive reactions, lowered self-esteem and lessening of "exterofective personality functions" Restlessness, irritability, alcoholism, anxiety and depression, aggressive and hostile behaviour an relationship difficulties were among the most frequent symptoms observed among hospitalised US Army A ̛⿱ Forces combat crews suffering operational fatiguen Among a group of World War II veterans at the LœS Angeles Veterans' Administration Mental Hygieng Clinic with traumatic war neurosis, the following 
symptoms were shown almost without exception: intense anxiety, tension, depression and a tendency to sudden, explosive, aggressive reactions ${ }^{4}$. A twenty year follow up of a World War II combat fatigue patient group showed a worsening over time of a number of symptoms including irritability, restlessness and depression; one fifth complained of problem drinking and, in three quarters, symptoms interfered with their providing for their families. More than one third were unemployed ${ }^{5}$. Veterans of the Egyptian Military with chronic traumatic war neurosis commonly presented with bouts of free-floating anxiety, aggressive behaviour with marked irritability, impotence and depressive reactions. Broken homes and divorces were not infrequent sequelae $e^{6}$. Part of the war sailor syndrome, described among survivors of the Norwegian Merchant Navy of World War II, were fatigue, irritability, emotional lability, impotence, restlessness and lack of initiative ${ }^{7}$. Both US and Australian Vietnam veterans in psychiatric treatment settings have demonstrated high rates of depression, anxiety, angry outbursts, suicide attempts, criminal convictions, family and marital disturbances and alcohol and drug abuse ${ }^{8-9}$.

However, the actual relationship of these distressing symptoms and disruptive behavioural abnormalities to the stresses of active service has been inadequately addressed. After all, aggressivity, self-destructive actions, alcohol and drug abuse, as well as family and employment dysfunctions, are the ways young adult males, in general, usually manifest their psychopathology ${ }^{10}$.

Only two studies using DSM-III operational criteria have attempted to determine the frequency with which such associated disturbances can be identified in patients with PTSD ${ }^{11-12}$. These were both conducted on US Vietnam veterans in psychiatric treatment settings and both described high rates of impulsive violence, suicide attempts, anti-social behaviour, alcoholism and drug abuse. However, neither study was controlled and they leave one wondering whether there is a specific association between PTSD and these features or whether the findings simply reflected the anticipated psychopathology of a group of disturbed, young adult males, from predominantly working class backgrounds, seeking psychiatric attention.

In an attempt to answer this question, the present study compared the rates of these behavioural abnormalities between groups of psychiatrically hospitalised Australian Vietnam veterans with PTSD and those free of the disorder.

A preliminary note about Australian military involvement in South Vietnam may be helpful. This paralleled that of the US with introduction of advisers in 1962, combat troops in 1965 and with the maximum strength of 8200 being reached in 1968. Of the fifty thousand personnel who served in Vietnam, 494 were killed, 2398 were maimed or injured and, in 1982, 6800 were receiving disability pensions $(544$ for neuropsychiatric disorders).

Some 300 Vietnam veterans have been treated as inpatients by the psychiatry department of the Repatriation Hospital in Sydney, of whom forty-five per cent have been diagnosed as suffering from a PTSD ${ }^{13}$.

\section{Method}

All Vietnam veterans hospitalised under the author's care in the Sydney Repatriation hospital from January 1981 to October 1984 were included as subjects $(\mathrm{N}=$ 50). Information was gathered primarily by standard psychiatric assessment interviews lasting some sixty minutes and was augmented by social work reports from family members (usually spouses) and any relevant material which surfaced in subsequent psychotherapy. This last usually took the form of more detail about combat experiences. All cases had routine physical examinations and investigations which always included base line haematology and biochemistry, syphilis serology, fasting blood sugars and electroencephalograms.

In addition, each veteran was administered briefrating scales for anxiety, depression and PTSD to introduce a measure of quantitative corroboration with the interview diagnoses of these disorders (Hamiltono Anxiety Rating Scale ${ }^{14}$, Hamilton Depression Rating Scale $e^{15}$ and the Impact of Event Scale ${ }^{16}$ ).

DSM-III operational criteria were used throughout when making diagnoses.

Of the fifty ex-servicemen in the sample, there were no cases of psychosis apart from those directly attributable to alcohol or drug toxicity or withdrawal. Two cases with disabling brain damage (one from a severe head injury sustained in a motor bike accident and one with alcoholic dementia) were excluded as adding an unacceptable bias in the direction of aggressive impulsivity and low frustration tolerance.

The experimental group $(\mathrm{N}=21)$ comprised those veterans with a diagnosis of PTSD. All had seen combat, been in situations of considerable personal stress and danger and had been confronted by scenes of death and injury. These often took the form of comrades severely mutilated by land mine explosions or of casualties from among the local Vietnamese population (frequently non-combatants).

The control group $(\mathrm{N}=27)$ showed an absence of diagnostic features of PTSD and had had no exposure to combat or to enemy action that would have significantly imperilled them. Most (22) had served in non-field force units in the relatively secure logistic support base at Vung Tau.

There was no difference between each group in terms of age (mean 34 years), length of service in South Vietnam (mean 10.5 months) or duration of hospitalisation (mean 22 days). 


\section{Results}

Table 1 lists the features said by DSM-III to be associated with or complicating PTSD and their frequencies in both the experimental and control groups. As can be seen, a similar pattern of antisocial

\section{Table I}

Frequency of DSM-III associated features of PTSD among Veterans with and without this disorder.

\begin{tabular}{|c|c|c|c|c|}
\hline Disorder & $\begin{array}{l}\text { Veterans with } \\
\text { PTSD }(\mathbf{N}=21)\end{array}$ & & $\begin{array}{l}\text { Veterans } \\
\text { PTSD (N }\end{array}$ & hout \\
\hline & number pe & erce & nt numbe & ercen \\
\hline Depression & 17 & 80 & 23 & 84 \\
\hline Anxiety & 7 & 32 & 13 & 48 \\
\hline Alcohol abuse & 18 & 88 & 19 & 72 \\
\hline Impulsive violence & 13 & 60 & 15 & 56 \\
\hline Suicide attempts & 11 & 52 & 12 & 44 \\
\hline Drug abuse & 10 & 48 & 8 & 28 \\
\hline $\begin{array}{l}\text { Marital disruption, } \\
\text { separation or divorce }\end{array}$ & 18 & 88 & 17 & 64 \\
\hline Sexual dysfunction & 7 & 32 & 9 & 32 \\
\hline $\begin{array}{l}\text { Unemployed for } \\
\text { last six months }\end{array}$ & 14 & 68 & 16 & 60 \\
\hline $\begin{array}{l}\text { Convictions since } \\
\text { repatriation }\end{array}$ & 8 & 40 & 9 & 32 \\
\hline
\end{tabular}

behaviour, aggressive impulsivity, suicide attempts and alcohol and drug abuse, along with symptoms of depression and anxiety emerged in both groups. There were no differences in rates for any of the variables that actually reached statistical significance $(P<.05$ using a chi square test of independence).

Table 2 lists the mean scores for the experimental and control groups on the Hamilton Anxiety and Depression Rating Scales and the Impact of Event Scale. Those for anxiety and depression are within the range manifested by psychiatric cases diagnosed as suffering from anxiety and depressive states ${ }^{14-15}$.

The Vietnam veterans with a diagnosis of PTSD had a mean Impact of Event Scale score of 51. This compares with a score of 40 for a group receiving out-patient psychotherapy at the University of California for this disorder ${ }^{17}$ and a score of 2.5 for male medical students who had just commenced in the anatomy dissection room $^{16}$.

It can thus be concluded that, at least among hospitalised Vietnam veterans, the features said by DSM-III to complicate and be associated with PTSD are not at all specific and can occur with equal frequency among ex-servicemen who saw combat and those who did not.
Note to Table I on DSM-III diagnostic categories.
"Depression" includes $(\mathrm{N}=40)$

"Anxiety" includes $(\mathrm{N}=20)$

"Impulsive violence" includes $(\mathrm{N}=28)$

"Sexual dysfunction" includes $(\mathbf{N}=16)$ a. Major Depression $22.5 \%$

b. Adjustment Disorder with Depressed Mood 50\%

c. Dysthymic Disorder $27.5 \%$

a. Generalized Anxiety

Disorder $40 \%$

b. Adjustment Disorder with

Anxiety $45 \%$

c. Panic Disorder 15\%

a. Intermittent Explosive

Disorder $21.4 \%$

b. Psychogenic Amnesia/fugue $48 \%$

c. Antisocial Personality

Disorder $35.7 \%$

a. Inhibited Sexual Excitement $68.7 \%$

b. Premature Ejaculation $25 \%$

c. Ego syntonic homosexuality $6.3 \%$

Table II

Mean scores for experimental and control groups on s measuring anxiety, depression and PTSD.

Instrument

Hamilton Anxiety Scale

Veterans with PTSD

Veterans without PTSD

Hamilton Depression Scale

32.3

34.5

Impact of Event Scale

20.7

23.3

51

\section{Discussion}

These findings are in agreement with much recen research which shows that while some 40 per cent of: Vietnam veterans continue to manifest features of PTSD $^{18}$, overall, their rates of alcoholism, suicide criminal convictions, violence and drug abuse are n\$ higher than for their peers from similar socioeconomi backgrounds who saw no active military service ${ }^{19-2 \frac{6}{3}}$ Indeed, severity of combat exposure seems to correlate. only with the severity of PTSD ${ }^{18,25}$ and depressive symptoms ${ }^{26}$. While the former appears to be pursuing chronic and even deteriorating course ${ }^{27}$, the latter hag returned to baseline levels by the end of the third post repatriation year ${ }^{28}$.

The findings of this present study are also congruento with those of a major, controlled, follow up study of Swedish soliders who saw active service with the United Nations forces in the Congo in 1961-62 ${ }^{29}$. Those witt combat exhaustion demonstrated no excess of "actine 
out" type psychopathology and, indeed, their levels of physical and psychological symptomatology, occupation, income, social status and marital stability were remarkably similar to the controls. There were, also, no differences between those veterans with combat exhaustion and the controls on two objective measures of psychopathology (the Eysenck Personality Inventory and the Marke-Nyman Temperament Scale).

There is little evidence from either this present study or from the literature of any specific association between a diagnosis of PTSD (or traumatic war neurosis) and violent impulsivity, alcoholism, drug abuse, selfdestructive behaviour, anxiety and depression.

Therefore, it should not necessarily be assumed that when ex-servicemen manifest such disruptive and antisocial behaviours or complain of neurotic symptoms that 1 their war service is always a major aetiological factor.

\section{REFERENCES}

1 American Psychiatric Association. Diagnostic \& Statistical Manual of Mental Disorders, Third Edition. Washington, DC: APA, 1980.

2 KARDINER A. The Traumatic Neuroses of War. New York: Paul Hoeber, 1941.

3 Grinker R R. Psychiatric disorders in combat crews overseas \& in returnees. Med Clin North Am 1945; 29: 729-739.

4 Futterman S. and Pumpian-Mindlin E. Traumatic war neuroses five years later. Am J Psychiatry 1951; 108: 401-408.

5 Archibald H C and Tuddenham R R. Persistent stress reaction after combat. A 20 year follow-up. Arch Gen Psychiatry 1965; 12: 475-481.

6 El Sudany El and Rayes M. Traumatic war neurosis Egyptian experience. J R Army Med Corps 1982; 128: 67-71.

7 Askevold F. War sailor syndrome. Psychother Psychosom 1976; 27: 133-138.

8 BRAATZ E A et al. The young veteran as psychiatric patient in three eras of conflict. Milit Med 1971; 136: 455-457.

9 BOMAN B. Psychiatric disturbances among Australian Vietnam veterans. Milit Med 1985; 150 (in press).

10 MAZER M. Two ways of expressing psychological disorder: the experience of a demarcated population. Am J Psychiatry 1972; 128: 933-937.

11 Sierles F S et al. Post Traumatic Stress Disorder \& concurrent psychiatric illness: a preliminary report. Am J Psychiatry 1983; 140: 1177-1179.

12 Escobar J I et al. Post Traumatic Stress Disorder in Hispanic Vietnam veterans. J Nerv Ment Dis 1983; 171: 585-596.

13 Streimer J et al. The psychosocial adjustment of hospitalised Vietnam veterans. Paper presented at Annual Congress Royal Austrailian \& New Zealand College of Psychiatrists, Perth, 1983.
14 Hamilton M. The assessment of anxiety states by rating. Brit J Med Psychol 1959; 32: 50-55.

15 Hamilton M. A rating scale for depression. $J$ Neurol Neurosurg Psychiatry 1960; 23: 56-62.

16 Horowitz M et al. Impact of Event Scale: a measure of subjective stress. Psychosom Med 1979; 41: 209-218.

17 Horowitz M et al. Signs \& symptoms of Post Traumatic Stress Disorder. Arch Gen Psychiatry 1980; 37: 85-92.

18 FRYE J S AND STOCKTON R A. Discriminant analysis of Post Traumatic Stress Disorder among a group of Vietnam veterans. Am J Psychiatry 1982: 139: 52-56.

19 Ewalt J R. What about the Vietnam veteran? William C. Porter Award Lecture. Milit Med 1981 ; 146: 165-167.

20 Senate Standing Committee on Science \& the Environment. Pesticides \& the Health of Austrialian Vietnam Veterans - First Report. Veteran Mortality, Canberra: Australian Government Publishing Service, 1982.

21 STARR P. The Discarded Army: Veterans after Vietnam. New York: Charterhouse, 1973.

22 NACE E P et al. Adjustment among Vietnam veteran drug users two years post service. Stress Disorders Among Vietnam Veterans. C R Figley ed New York: Brunner/ Mazel, 1978.

23 Robins $\mathrm{L} \mathrm{N}$ et al. Narcotic use in Southeast Asia \& afterward. Arch Gen Psychiatry 1975; 32: 955-961,

24 Strange R E AND Brown D E. Home from the war: a study of psychiatric problems in Vietnam Returnees. Am J Psychiatry 1970; 127: 488-492.

25 PENK $W E$ et al. Adjustment differences among male substance abusers varying in degree of combat experience in Vietnam.J Consult Clin Psychol 1981; 49: 426-437.

26 NACE E P et al. Depression in veterans two years after Vietnam. AmJ Psychiatry 1977; 134: 167-170.

27 HoRowitz M and SOLOMON G. F. Delayed stress response syndromes in Vietnam veterans. Stress Disorder Among Vietnam Veterans. C R Figley ed New York: Brunner/ Mazel, 1978.

28 Helzer J E et al. Depression in Vietnam veterans \& civilian controls. Am J Psychiatry 1979; 136: 526-529.

29 KetTNer B. Combat strain \& subsequent mental health. A follow-up study of Swedish soldiers serving in the United Nations forces 1961-62. Acta Psychiatr Scand (Suppl 230) 1972.

\section{Acknowledgement}

The author gratefully acknowledges the permission of the Australian Department of Veterans' Affairs to publish the data in this article. Any opinions expressed are those of the author and are not necessarily those of the Department. 